\title{
Plasminogen Activator Activity in Cultures from Human Tissues. An Immunological and Histochemical Study
}

\author{
Maria B. Bernik and Hau C. KwaAn \\ From the Department of Medicine, Northwestern University Medical School, \\ Chicago, Illinois 60611; the Department of Research, Chicago Wesley \\ Memorial Hospital, Chicago, Illinois 60611; and the Hematology Section, \\ Veterans Administration Research Hospital, Chicago, Illinois 60611
}

A B S T R A C T Human tissues and cells from pre- and postnatal life were cultivated and studied for plasminogen activator activity. Cultures were obtained from kidney, renal blood vessels, ureter, bladder, lung, and heart. Local activator activity of cells was demonstrated by histochemical techniques. Activator released by cells into the supernatant culture media was assayed by fibrin plate techniques and was investigated for immunological identity using specific antisera to an activator of human origin, urokinase (UK).

Plasminogen activator was produced in primary cultures where cells retain specific functions and generally reflect the enzyme pattern of the tissues of origin. Cells from fetal and adult sources were found to yield activator antigenically identical to $U K$, as well as activator activity which differed from that of UK in immunoassays and which may represent tissue type activator. Such activity was released after injury or death of cells while UK was produced in cultures containing live, metabolizing cells.

Primary cultures of kidney confirmed that this organ is a rich source of $\mathrm{UK}$ and demonstrated, in addition, that $\mathrm{UK}$ is produced from the early stages of gestation and in increasing amounts thereafter. However, primary cultures also demonstrated that the ability to produce $\mathrm{UK}$ is not limited to the kidney but is a function of cells which are distributed widely in body tissues. Thus, activator antigenically identical to UK accumulated progressively after many refeedings in culture supernates of fetal lung and ureter, as well as in supernates of renal blood vessels of adults. These findings indicate continuous formation of UK by the cultured cells and, furthermore, provide evidence of UK production in blood vessels. In cultures from other tissues, particularly

Abstract of preliminary results appeared in 1968 Fed Proc. 27: 272.

Received for publication 1 October 1968 and in revised form 24 April 1969. those from fetal heart and adult lung and bladder, investigation of activator was hindered by inhibitory activity which accumulated in the supernates. Such activity was derived from cells in culture and was directed selectively against $\mathrm{UK}$, indicating that inhibitor as well as UK are produced by cells of various organs of the body.

Plasminogen activator also was produced by serially propagated cells, diploid and heteroploid. However, only diploid cell lines retained activator activity of the original tissues and continued to produce activator antigenically identical to UK. In contrast, heteroploid line appeared to have lost the ability to form UK by yielded activator activity that differed from that of UK in immunoassays. Serially propagated cells thus provide an additional tool for in vitro study of plasminogen activator and may facilitate investigation of the fibrinolytic system in man.

\section{INTRODUCTION}

Plasminogen activators are present in body fluids and tissues. Although naturally occurring activators in man have not been fully characterized, various types have been distinguished including tissue, plasma, and urine activators. Tissue activator appears to be present in nearly all tissues (1-3) and may be released through injury and death of cells (2). Plasma activator is believed to originate from cells of blood vessels and can be released in blood in vivo after various stimuli (4-8). Activator in urine, urokinase (UK), is produced by kidney cells (9) but may also be derived from other sources $(10,11)$. Urokinase, tissue, and plasma activators differ from each other immunologically (8) and in other properties $(3,12)$. However, exact relationship among these activators, their origin, and their role in blood and local fibrinolytic events are not clear. 
Studies of adult human kidneys have indicated that cells in culture may facilitate the investigation of the origin, production, and identity of activator activity in man (9). Cells from the adult kidney in primary culture produced activator antigenically identical to that found in the urine, UK $(8,9)$. Activator activity also has been demonstrated in cultures from other human tissues, both from pre- and postnatal life (13-16), although identity of activator in these various cultures has not been fully explored.

Histochemical (9) and immunological techniques $(8,9)$ are applied to the present study to human tissues and cells in culture in an effort to further define activator activity in man. Plasminogen activator is investigated in primary cultures $(9,17,18)$ where cells exhibit many of their in vivo characteristics, retain specific functions, and generally reflect the enzyme pattern of the tissue of origin (18). Activator activity also is examined in serially propagated cells, both diploid and heteroploid $(17,19,20)$, to determine to what extent such cells retain activity of the original tissues and cells. Serially propagated cells represent an easily accessible source of a large number of cells for biological studies in vitro (18-21) and may provide an additional tool for the investigation of plasminogen activator activity in man.

\section{METHODS}

Kidney. Postnatal kidney tissue was obtained at nephrectomy from five adults and at necropsy from one full-term infant. The tissue was cut into fragments and parts were treated with $0.25 \%$ trypsin (Bacteriological Products, Difco Labs, Inc., Detroit, Mich., 1:250). Fragments and trypsinized cells were grown in primary culture $(9,17)$. Parts of cortex and medulla were cultured separately.

Fetal kidney cells in primary culture obtained at the following stages of development: 26-32 wk, 16-20 wk, and 12$14 \mathrm{wk}$ of gestation. ${ }^{1}$

Fetal kidney cells from a heteroploid, ${ }^{2}$ as well as from a diploid line $^{3}(17)$, were obtained after the 30 th passage and were maintained in culture by trypsinizing the cells and splitting and replanting the cell suspensions (19) twice weekly.

Renal blood vessels. Branches of the main renal artery and of renal veins were carefully removed from the hilum of kidneys obtained at nephrectomy from adults. The blood vessels were washed in Hanks' balanced salt solution (HBSS), freed of debris and fatty tissue, cut into fragments under a dissecting microscope, and cultured as primary explants (9).

Ureter. Ureters from 16 to $20 \mathrm{wk}$ fetuses were cut into fragments and grown as primary explants (9).

\footnotetext{
${ }^{1}$ Primary human embryonic kidney, Flow Laboratories, Inc., Rockville, Md., and Microbiological Associates, Inc., Bethesda, Md.

${ }^{2}$ Human embryonic kidney cell line, Baltimore Biological Co., Baltimore, Md.

${ }^{3}$ MA human embryonic kidney cell line, Microbiological Associates, Inc., Bethesda, Md.
}

Bladder. Bladder tissue was obtained at surgery from two adults. The mucosa and parts of the submucosa were cut into fragments and grown in primary culture (9).

Lung. Postnatal lung tissue was obtained at surgery from four adults and at necropsy from one full-term infant. The tissue was cut into fragments and parts were trypsinized. Fragments and trypsinized cells were grown in primary culture (9).

Fetal lung cells in primary culture were obtained from 16 to 18 wk fetuses. ${ }^{4}$ Primary cultures also were subcultivated (19) for up to 20 passages by trypsinizing the cells and splitting and replanting the cell suspensions at 3-4 day intervals.

Subcultures of fetal lung cells from a diploid cell line (17), Wi 38 (19), were obtained at the 26th passage ${ }^{5}$ and were kept in culture to the 45 th passage. Cultures were trypsinized, split, and replanted at 3-4 day intervals.

Heart. Subcultures of fetal heart cells from 16 to $30 \mathrm{wk}$ fetuses were obtained at the third ${ }^{6}$ and twelfth $^{7}$ passages. These cells were maintained in culture to the thirteenth passage.

Tissues and cells were grown in Rose chambers (22), tubes, and flat bottles. Cells were implanted in Rose chambers with or without the strip of dialysis tubing (22). All cultures were incubated at $37^{\circ} \mathrm{C}$. Primary cultures were refed twice weekly while subcultures were refed at each trypsinization. Newborn agamma calf serum and fetal calf serum were used interchangeably in the culture media. Cultures of postnatal tissues received $20 \%$ serum in Eagle's basal medium (BME) (23). Cultures from fetal tissues were given $10 \%$ serum in BME or in Eagle's minimum essential medium (24). Phenol red indicator was present in both BME and minimum essential medium. Antibiotics, $100 \mathrm{U}$ of penicillin and $100 \mu \mathrm{g}$ of streptomycin $/ \mathrm{ml}$, were added to all culture media.

At varying intervals, the original culture media were changed to serum-free medium, BME, containing $0.2 \%$ gelatin to prevent adsorption of activator to the glass surfaces (25). In some of the cultures $2 \%$ serum was added to this medium. The amount of medium was adjusted to obtain approximately the same cell: medium ratio in all bottle and tube cultures. After the change of medium and after each subsequent refeeding, supernatant fluids were collected or sampled at 1-7 day intervals for periods up to $8 \mathrm{wk}$.

Cells in Rose chambers were observed during culture by phase-contrast microscopy and were followed by time-lapse cinematography, both before and after the change of media. The $\mathrm{pH}$ of supernatant media provided indication of the viability of cells grown in tubes and bottles (19). Additional information on viability and growth in these preparations was obtained by examining cultures macroscopically (19) and by periodically transplanting cells to Rose chambers where they could be observed in greater detail.

Fibrinolytic activity of cells in culture. Two methods were used to study the activity of cells. (a) A histochemical fibrin slide technique (9) was applied to cells from Rose chambers that were fixed after varying periods of culture.

\footnotetext{
${ }^{4}$ Primary human lung, Microbiological Associates, Inc., Bethesda, Md.

${ }^{5}$ Kindly supplied by Abbott Laboratories, North Chicago, Ill.

${ }^{6}$ Human fetal heart, Grand Island Biological Co., Grand Island, N. Y.

${ }^{\top}$ Human embryonic heart, Flow Laboratories, Rockville, Md.
} 
Cover slips containing the fixed cells were mounted on a microscope slide. $0.01 \mathrm{ml}$ bovine thrombin (Thrombin Topical, Parke, Davis, $20 \mu / \mathrm{ml}$ ) was pipetted onto the preparation and $0.06 \mathrm{ml}^{8}$ of bovine plasminogen-rich fibrinogen ${ }^{9}$ $(0.7 \%, \mathrm{pH} 7.8$, ionic strength 0.15$)$ was added and quickly mixed with the thrombin to form a fibrin film approximately $0.06 \mathrm{~mm}$ thick. ${ }^{8}$ Preparations were incubated in a moist chamber for $10-30 \mathrm{~min}$, fixed in $10 \%$ formaldehyde, and stained with Harris' alum hematoxylin.

(b) Living cells in culture were studied for fibrinolytic activity by exposing them to a thin layer of fibrin clot. The dialysis tubing, when present, was removed from Rose chambers and the cultures were refed. 1-3 days later the medium was withdrawn and the cells were washed with two changes of HBSS to remove traces of culture medium. Thrombin was injected into the chambers and allowed to flow over the cover slip on which the cells were growing. Excess thrombin was drained off. $0.15 \mathrm{ml}$ of fibrinogen was placed over the area containing cells and mixed with the thrombin by gently tilting the chamber. This formed a fibrin layer of even thickness which completely covered the cells and the glass cover slip on which they were growing. Lysis of such fibrin clots by cells in culture was monitored by phase-contrast microscopy and time-lapse cinematography during incubation at $37^{\circ} \mathrm{C}$

Cells also were studied for proteolytic activity in both methods by substituting plasminogen-rich with plasminogenfree fibrin obtained from bentonite adsorbed fibrinogen ${ }^{\circ}$ (26).

Fibrinolytic activity in supernatant culture media. Serumfree and serum-poor supernates were assayed by the fibrin plate technique using plasminogen-rich (27) and plasminogen-free fibrin (26). The two substrates were used to differentiate between plasminogen activator and nonspecific proteases. Such nonspecific proteolytic activity was not demonstrated in any of the supernates indicating that activity was due to plasminogen activator. Activity was plotted against different strengths of urokinase ${ }^{10}$ standards, and the results were expressed as CTA (Committee on Thrombolytic Agents, National Heart Institute) units.

Supernatant media from cultures which failed to show plasminogen activator were examined for inhibitory activity against activator and plasmin by the method of Brakman and Astrup (28). Supernates were mixed with equal volumes of UK standards $(9.6-0.6 \mathrm{CTA} \mathrm{U} / \mathrm{ml})$ and with activator which was extracted from human hearts by the method of Bachmann, Fletcher, Alkjaersig, and Sherry (3). The mixtures were assayed on plasminogen-rich fibrin plates. Samples of supernates also were mixed with equal volumes of glycerol-activated plasmin ${ }^{11}$ (29) (0.8-0.025 Remmert and Cohen $\mathrm{U} / \mathrm{ml}$ ) and tested on heated fibrin plates $(30)$. $\mathrm{UK}$ and plasmin standards, activator from human heart tissue, and control medium that had not been exposed to cells were assayed simultaneously.

Immunological study of plasminogen activator in supernatant culture media. Antiserum against human urokinase

\footnotetext{
${ }^{8}$ The amount of fibrinogen and the thickness of the fibrin were erroneously reported previously (9) as $0.6 \mathrm{ml}$ and $0.01 \mathrm{~mm}$, respectively.

${ }^{8}$ Kindly supplied by Dr. T. Astrup, James F. Mitchell Foundation, Washington, D. C.

${ }^{10}$ Kindly supplied by Abbott Laboratories, North Chicago, III.

${ }^{11}$ Kindly supplied by Dr. J. T. Sgouris, Michigan Department of Health Laboratories, Lansing, Mich.
}

was prepared in white New Zealand rabbits by subcutaneous injection of purified human urokinase ${ }^{10}$ having a specific activity of $35,000 \mathrm{CTA} \mathrm{U} / \mathrm{mg}$ protein. The rabbits were given weekly injections of $40,000 \mathrm{CTA} \mathrm{U}$ of urokinase with Freund's adjuvant and $0.5 \%$ human albumin. After $6 \mathrm{wk}$ the sera were collected, pooled, and adsorbed with human albumin to remove the antialbumin component. The antiserum neutralized the activity of UK standards when assayed by the fibrin plate method but did not neutralize the activity of streptokinase, of activator which was extracted from human hearts by the method of Bachmann et al. (3), or of activator obtained through stimulation with vasoactive drugs (8).

Anti-UK serum was used to identify immunologically activator activity in supernates of cultures $(8,9)$. Supernatant media were assayed immediately on collection from the cultures and after storage at $-20^{\circ} \mathrm{C}$ for periods up to 2 months. Activator in supernates was assayed simultaneously with UK standards on fibrin plates and on plates containing antiserum in a final concentration of $1: 1000$ in the fibrin substrate. Specific neutralization of activator by the antiserum, shown by a decrease of fibrinolytic activity, was differentiated from nonspecific inhibition by using control serum as described below. The degree of specific neutralization of activator in culture media was compared to that of UK standards and the results were expressed as percentage neutralization of activator activity.

Activity in supernates also was assayed with anti-UK serum prepared in guinea pigs ${ }^{12}(8)$ and with a $\gamma$-globulin fraction ${ }^{13}$ from antiserum to a highly purified UK preparation having a specific activity of $218,000 \mathrm{CTA} \mathrm{U} / \mathrm{mg}$ protein (31). The fraction was incorporated in the fibrin substrate in a concentration representing a $1: 50,000$ dilution of the original antiserum, while the guinea pig antiserum was used in 1:5000 concentration. In such concentrations, specific neutralizing effect of the two antisera on UK standards was identical to that of our antiserum, while $\gamma$-globulin fraction from control sera was not inhibitory even when undiluted (31) and whole control sera showed no inhibitory effect at 1:500 or higher dilutions. The three antisera also were similar in their neutralizing effect on fibrinolytic activity of activator in the supernates of cultures. Each sample of supernate was assayed with at least two of the antisera. There was less than $10 \%$ difference in the degree of specific neutralizing effect among the antisera.

\section{RESULTS}

Primary cultures of postnatal kidney. Cultures of adult kidneys were similar to those described previously (9). Cells began to grow 2-4 days after implantation. Cells from vessels, interstitium, and tubules exhibited brisk mitosis up to $6 \mathrm{wk}$ of culture. Mitosis then decreased, but cells remained viable for periods up to 12 wk, as observed by phase-microscopy and time-lapse cinematography. Cultures of neonatal kidney were similar in appearance and behavior to those of adult kidney.

\footnotetext{
${ }^{12}$ Kindly supplied by Dr. C. S. Kusinski, University of Colorado Medical Center, Denver, Colo.

${ }^{13}$ Kindly supplied by Dr. W. F. White, Abbott Laboratories, North Chicago, I11.
} 


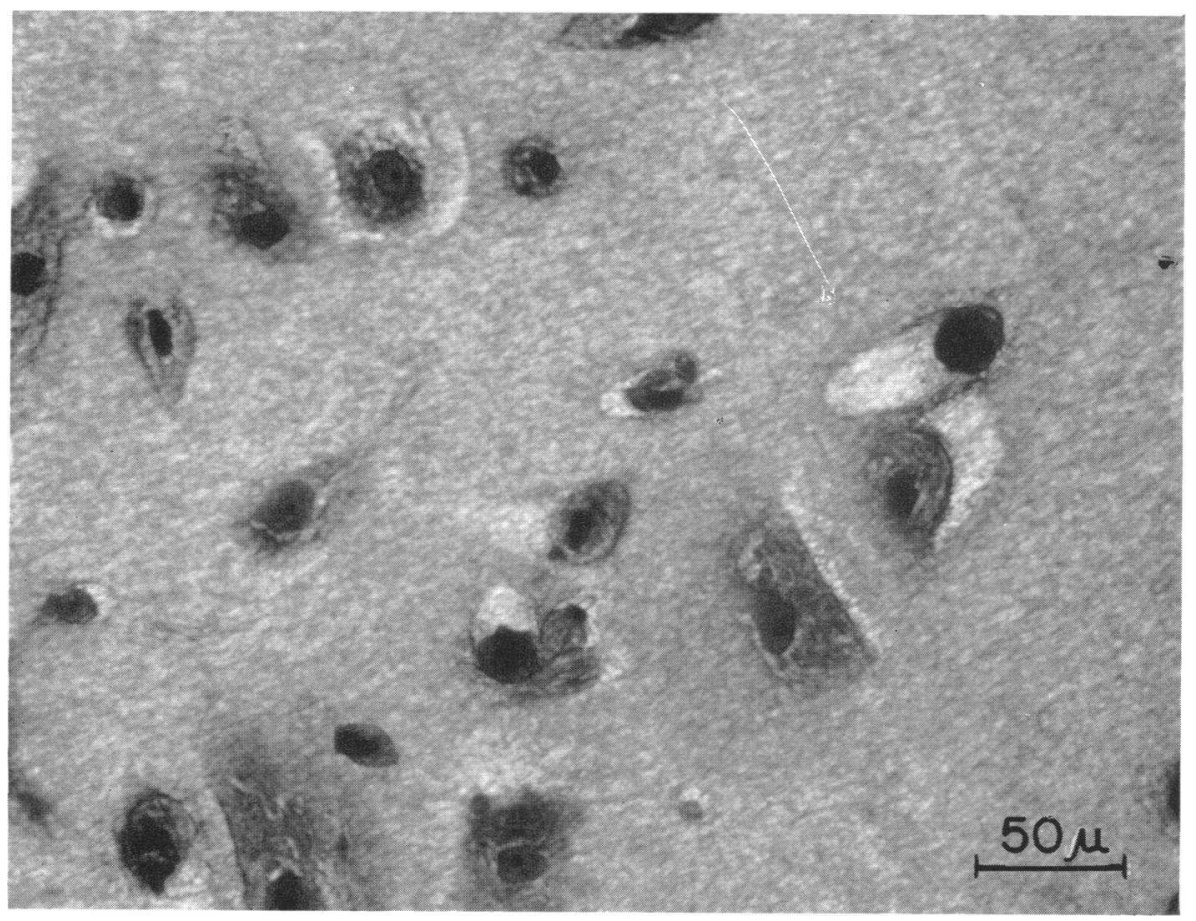

FIGURE 1 Cells from a fixed culture of human kidney tissue. After 10 min incubation with plasminogen-rich fibrin, pale zones of lysis have formed around some of the cells, indicating fibrinolytic activity. Harris' alum hematoxylin stain.

Adult and neonatal kidney cells exhibited activator activity when fixed cells were studied by the fibrin slide technique, as described previously (9). Lytic areas were thus observed in up to $5 \%$ of the fixed cells after 5-10 min incubation with plasminogen-rich fibrin (Fig. 1). However, greater activator activity was elicited when living cells were exposed to plasminogen-rich fibrin during culture in Rose chambers (Fig. $2 a, b, c$ ). Fibrinolytic activity was then exhibited by up to $30 \%$ of the cells. Lysis started within $30 \mathrm{sec}$ or less after the fibrin clots were formed over the surface of cells. Large lytic areas became confluent within 1-2 min and the entire fibrin layer usually was lysed within $30 \mathrm{~min}$. Most of the active cells in these cultures remained viable after lysing the clots and some continued to divide upon refeeding. In cultures of cortex, lysis started as promptly as in cultures of medulla but it usually progressed more slowly. Plasminogen-free fibrin was not lysed by kidney cells in culture even after $6 \mathrm{hr}$ or more of incubation, indicating that lysis of plasminogen-rich fibrin was due to plasminogen activator.

In supernates, plasminogen activator was studied after cultures were changed from the original serum-rich medium to BME, 1-4 wk after implantation. In serumfree medium, cells frequently continued to divide for several days and survived for periods up to $8 \mathrm{wk}$. Activator activity was detected in the supernates begin- ning 1-3 days after the change of medium. The amounts increased thereafter, ranging from 1.0 to $10 \mathrm{CTA} \mathrm{U} / \mathrm{ml}$ per day (Fig. 3). Activity reaccumulated in the media after each refeeding until cells began to die towards the end of the culture period. With death of cells, activator content in the media dropped. The correlation among activity in the medium, viability of cells, and time of exposure of medium to cells was similar to that observed previously in cultures of adult human kidney (9).

Neutralization assays with the anti-UK sera revealed that activator in supernates of adult and neonatal kidney cultures was antigenically identical to UK. 6-12 samples from each culture, containing 1.5-70 CTA U/ml were assayed. There was $100 \%$ neutralization of activator activity as compared to that of UK standards. Such complete neutralization was observed both in fresh samples of media and in media that had been stored, although with repeated thawing there was up to $30 \%$ loss of activity.

In media obtained towards the end of the culture period when cells began to die and activity in the supernates decreased, neutralization by the anti-UK sera was not complete, but ranged from 80 to $90 \%$. To test if incomplete neutralization was related to cell injury or death, kidney cultures were studied after cells were subjected to mechanical trauma. The results of these ex- 

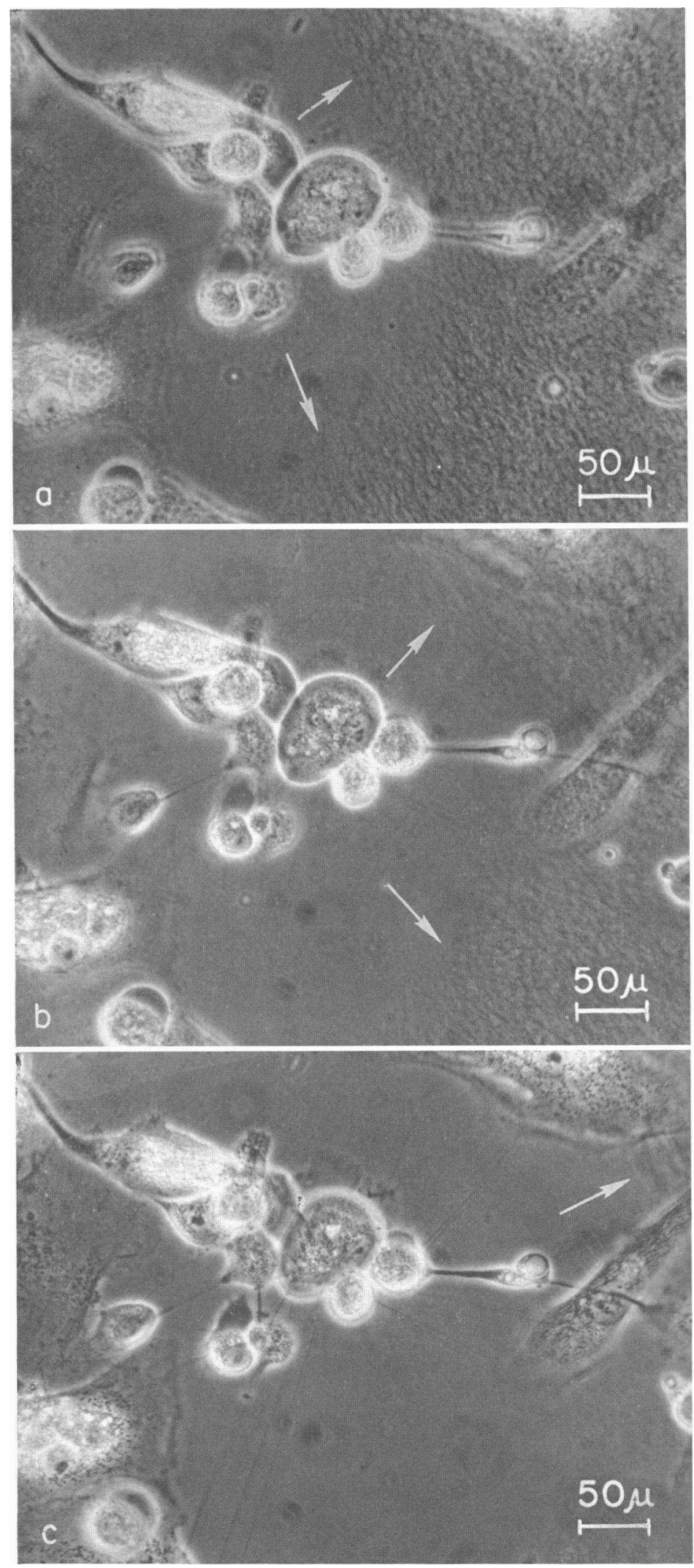

FIGURE 2

1744 M. B. Bernik and H. C. Kwaan 
CULTURE MATERIAL

CT A UNITS/ML/DAY

\begin{tabular}{|c|c|c|c|c|c|c|c|c|}
\hline & No. & & & & oge & & & Range \\
\hline & & 1 & 2 & 3 & 4 & 5 & 6 & 7 \\
\hline KIDNEY & & & & & & & & \\
\hline Fresh fragments & 5 & $\square$ * & & & & & & $0.5-1.0$ \\
\hline Fresh fragments, stimulated & 3 & 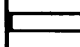 & & 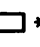 & & & & $2.0-4.0$ \\
\hline Primary culfures & 30 & 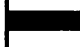 & & & & $\mathbf{0}$ & & $1.0-10.0$ \\
\hline Traumatized primary explants & 3 & $\square$ & & & & & & $1.0-1.5$ \\
\hline RENAL BLOOD VESSELS & & & & & & & & \\
\hline Fresh fragments & 2 & $\Xi^{*}$ & & & & & & $0.5-1.0$ \\
\hline Primary culfures & 3 & 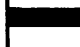 & & & & & & $1.5-2.0$ \\
\hline BLADDER & & & & & & & & \\
\hline Fresh frogments & 4 & $\Xi *$ & & & & & & $0.5-1.0$ \\
\hline Primary culfures & 4 & \pm & & & & & & \\
\hline LUNG & & & & & & & & \\
\hline Fresh frogments & 4 & $\square$ * & & & & & & $0.5-1.0$ \\
\hline Primary culfures & 15 & $\neq e$ & & & & & & \\
\hline
\end{tabular}

FigURE 3 Plasminogen activator activity in the supernates of cultures from postnatal tissues. Horizontal bars represent average amounts of activator in CTA units/ml per day. Ranges are given in the column on the right. Activity that was neutralized specifically by antisera to human urokinase is shown as solid bars. $*=30$ min samples; $\ddagger=$ plasminogen activator activity demonstrated in cells but not in supernates; $\S=$ inhibitory activity present in supernates; $\|=$ exposed to vasoactive drugs (nicotinic acid or acetylcholine).

periments are summarized in Fig. 3. Five tube cultures of primary explants of adult kidney, yielding 4-5 CTA $\mathrm{U} / \mathrm{ml}$ per day and showing complete $(100 \%)$ neutralization by anti-UK sera, were selected for study. After assaying the supernatant media daily for $1 \mathrm{wk}$, explants were removed from three of the tubes and were minced in a quartered Petri dish containing HBSS. The freshly cut pieces were allowed to sit in HBSS for 15-20 min at room temperature. The cell-free supernatant HBSS was assayed and was found to contain activator activity. However, only $30-40 \%$ of the activity was neutralized by the antisera indicating that cell injury or death mediate release of activator other than UK. Incomplete neutralization persisted after cut fragments were reimplanted and until outgrowth reappeared. Activity in the medium then began to increase and complete neutralization by the antisera was noted again. In contrast, when reimplanted tissue failed to survive and grow, yield of activator in supernates remained low (1.0 CTA $\mathrm{U} / \mathrm{ml}$ or less) and partial neutralization persisted.

Activator activity that differed from that of UK in immunoassays also was found in fresh kidney specimens before the tissue was cultured, as shown in Fig. 3. The specimens were cut, washed, and then incubated for 10 30 min in HBSS and in HBSS containing nicotinic acid $(0.1 \mathrm{mg} / \mathrm{ml})$ or acetylcholine $(20 \mu \mathrm{g} / \mathrm{ml})$ which have been shown to stimulate the release of plasminogen activator in vivo $(6,8)$ and in isolated organs in vitro (32). All fragments yielded activator activity in supernatant HBSS, but those stimulated with nicotinic acid or acetylcholine released 3- to 5-fold greater activity, particularly when fragments were derived from the medulla. Activity failed to be neutralized specifically by the anti-UK sera, although that released through stimulation was inhibited by normal, control sera in dilutions up to $1: 5000$. As shown in Fig. 3, kidney cells began to yield activator antigenically identical to UK after the tissue was implanted in primary culture and cells survived or grew. During culture, exposure to vasoactive drugs (acetylcholine and nicotinic acid) no longer elicited either increase in activator activity or activity that differed from that of UK in immunoassays.

Primary cultures of fetal kidneys. Studies were made using tissue from three different stages of development:

Figure 2 Cells from a living culture of human kidney tissue after exposure to plasminogen-rich fibrin. Arrows point to a zone of lysis in the center of the field. The lytic areas is enlarging rapidly and shows poorly defined borders of fibrin. $15 \mathrm{sec}$ have elapsed between each sequence. Phase-contrast photomicrographs. 


\section{CULTURE MATERIAL}

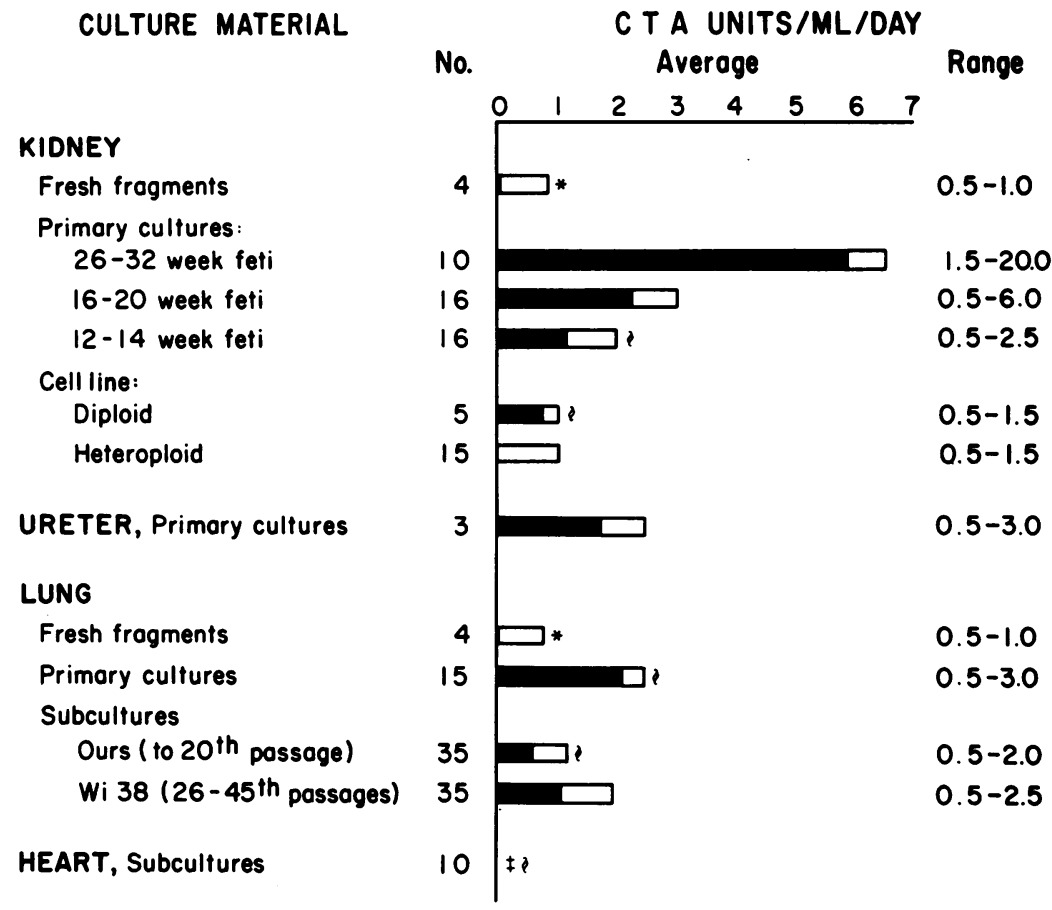

FIGURE 4 Plasminogen activator activity in the supernates of cultures from fetal tissues. Horizontal bars represent average amounts of activator in CTA units $/ \mathrm{ml}$ per day. Ranges are given in the column on the right. Activity that was neutralized specifically by antisera to human urokinase is shown as solid bars. $*=30$-min samples; $\ddagger=$ plasminogen activator activity demonstrated in cells but not in supernates; $\S=$ inhibitory activity present in supernates.

26-32 wk, 16-20 wk, and 12-14 wk of gestation. Plasminogen activator activity was demonstrated in supernatant HBSS of freshly cut fragments before culture, and in cells and media during culture. The findings are summarized in Fig. 4. As in the adult kidney, UK type activator activity was elicited by immunoassays only after cells were implanted and survived or grew in culture. Activity which accumulated in supernates during culture of fetal kidney cells was neutralized by anti-UK sera though the degree of neutralization and amounts of neutralized activity varied with the gestational age, as shown in Fig. 4.

In cultures from 26- to 32-wk fetuses, activator activity was similar to that of neonatal and adult kidney tissue. Activity was detected in the supernates 1-2 days after cultures received $\mathrm{BME}$, and then continued to accumulate for 4-6 wk in amounts ranging from 1.5 to 20 CTA $\mathrm{U} / \mathrm{ml}$ per day (average 6.5). The degree of neutralization by the antisera ranged from 70 to $95 \%$ (average $90 \%$ ).

In cultures from 16- to 20 -wk fetuses, activator activity accumulated in the media in lesser amounts, 0.56.0 CTA U/ml per day (average 3.0). Degree of neutralization also was less complete than in cultures of $26-$
32 wk fetuses and ranged from 50 to $85 \%$ (average $75 \%)$.

In cultures from 12- to 14-wk fetuses, activator activity also was demonstrated in cells and in supernatant media. However, activity in the supernates was elicited only after cultures were refed serum-free medium several times. During the first two to four refeedings, supernates yielded inhibitory activity which was directed against UK. Supernates that were exposed to cells for periods ranging from 1 to 3 days completely inhibited the activity of UK standards of 1.2-0.6 CTA U/ml. Supernates showed no inhibitory activity against plasmin or against activator extracted from human heart tissue. After cultures were refed with BME two or more times, inhibitory activity in the supernates dropped and activator activity began to accumulate in amounts up to $2.5 \mathrm{CTA} \mathrm{U} / \mathrm{ml}$ per day. Degree of neutralization by anti-UK sera ranged from 30 to $70 \%$ (average $60 \%$ ).

Cell lines from fetal kidneys. Diploid and heteroploid cell lines were investigated for plasminogen activator activity after cells had been subcultured for 30 or more passages. Both lines exhibited active cells though the number of such cells was small, $0.1 \%$ or less of the total population. Both lines also yielded activator activity in 
the supernates when cultures were changed from their regular medium to $\mathrm{BME}$ or to $\mathrm{BME}$ containing $2 \%$ serum. Results are summarized in Fig. 4.

The heteroploid line survived only 1-3 days in serumfree medium but when $2 \%$ serum was added to $\mathrm{BME}$ the cells were maintained in culture for 2-4 months and activator activity accumulated in supernates in amounts up to $1.5 \mathrm{CTA} \mathrm{U} / \mathrm{ml}$ per day. Diploid line survived in $\mathrm{BME}$ for 3-5 wk and activator activity was demonstrated in 5 of 15 culture supernates. The remaining cultures yielded inhibitory activity which was directed against $\mathrm{UK}$, and which continued to accumulate in supernates throughout the culture period.

Activator activity of the two cell lines differed immunologically when assayed with anti-UK sera. As shown in Fig. 4, activity from the diploid line was similar to that of primary fetal cultures and was neutralized by the antisera indicating that, after repeated subcultures, cells had retained ability to form activator antigenically identical to UK. In contrast, heteroploid line appeared to have lost such ability and yielded activator whose fibrinolytic activity was not neutralized by the anti-UK sera.

Primary cultures of ureter. Explants of fetal ureters began to show outgrowth within $16 \mathrm{hr}$ of implantation. Outgrowths consisted of mixed populations of cells from all layers, predominantly from the mucosa and submucosa. As shown by summary of results in Fig. 4, plasminogen activator activity from the ureter was similar to that observed in cultures of fetal kidneys of the same gestational age, 16-20 wk. In serum-free medium, cultures of ureter yielded activator activity in amounts up to $3.0 \mathrm{CTA} \mathrm{U/ml} \mathrm{per} \mathrm{day.} \mathrm{Activity} \mathrm{was} \mathrm{neutralized} \mathrm{by}$ the anti-UK sera. The degree of neutralization ranged from 30 io $90 \%$ (average $70 \%$ ).

Primary cultures of renal blood vessels. Renal arteries and veins were studied jointly since amounts of tissue material did not permit separate investigation. Plasminogen activator activity was demonstrated in supernatant HBSS of freshly cut fragments before culture as well as in cells and media during culture. The findings are summarized in Fig. 3. Activity from freshly cut fragments was similar to that of other tissues before culture and was not neutralized by anti-UK sera. However, activator activity antigenically identical to that of UK accumulated in supernates after the blood vessels were implanted and cells survived or grew in culture.

Outgrowth from explants of renal vessels usually was scant and consisted of a mixture of cells, macrophage, fibroblast, and epithelioid. However, large numbers of cells remained viable within explants as observed by time-lapse cinematography. Plasminogen activator activity was demonstrated in supernates when cultures were changed from their regular serum-rich medium to BME, 2-3 wk after implantation. Although supernates first yielded inhibitory activity, activator activity began to accumulate after the second or third, and then after each subsequent refeeding with $\mathrm{BME}$ until cultures died 3-4 wk after the change of medium. Activator activity which accumulated in supernates was neutralized almost completely by anti-UK sera, as shown in Fig. 3, indicating that cells from blood vessels produce and release UK type activator.

Primary cultures of bladder. Explants of adult bladder tissue began to show outgrowth 2-3 days after implantation. Cells emerged from the epithelial layer and the lamina propria and, to a lesser extent, from the submucosa, giving rise to a heterogeneous population of cells.

Freshly cut fragments of bladder yielded plasminogen activator activity in supernatant HBSS before culture. as shown in Fig. 3. In living cultures, however, activator activity was demonstrated only in cells while supernates showed inhibitory activity which was directed against UK. Serum-free supernates that were exposed to bladder cells for 1-7 days were found to inhibit completely the activity of UK standards of 4.8-1.2 CTA $\mathrm{U} / \mathrm{ml}$. The supernates were not inhibitory towards plasmin or towards activator extracted from human heart tissue. Inhibitory activity against $\mathrm{UK}$ continued to accumulate until bladder cells died, 2-3 wk after they received serum-free medium.

Primary cultures of postnatal lung. Plasminogen activator activity was studied both before and after the tissue was grown in primary culture as shown in Fig. 3. Activator activity was readily demonstrated in supernatant HBSS of freshly cut fragments. Such activity was similar to that found in other tissues before culture. i.e. kidney and bladder, and was not neutralized by the anti-UK sera. During culture, however, lung tissue yielded marked inhibitory activity which hindered assays of activator in the supernates, although activator activity was demonstrated locally in lung cells.

Primary explants of adult and neonatal lung began to show outgrowth 2-5 days after implantation. Outgrowths consisted of a mixture of cells-macrophages, leukocytes, ciliated cells, contractile cells, epithelioid, and fibroblast-like cells. After 7-10 days of culture, fibroblast-like cells frequently began to predominate in the outgrowths. Time-lapse records indicated, however, that the cell population remained heterogeneous.

Supernates of lung cultures were examined for activator activity beginning 5-7 days after implantation. Cultures were then changed from their regular serumrich medium to BME. Some mitosis continued for several days and cells survived in serum-free medium up to $4 \mathrm{wk}$. Supernates failed to yield activator activity but showed marked inhibitory activity which was directed against UK. Serum-free supernatant media that were 

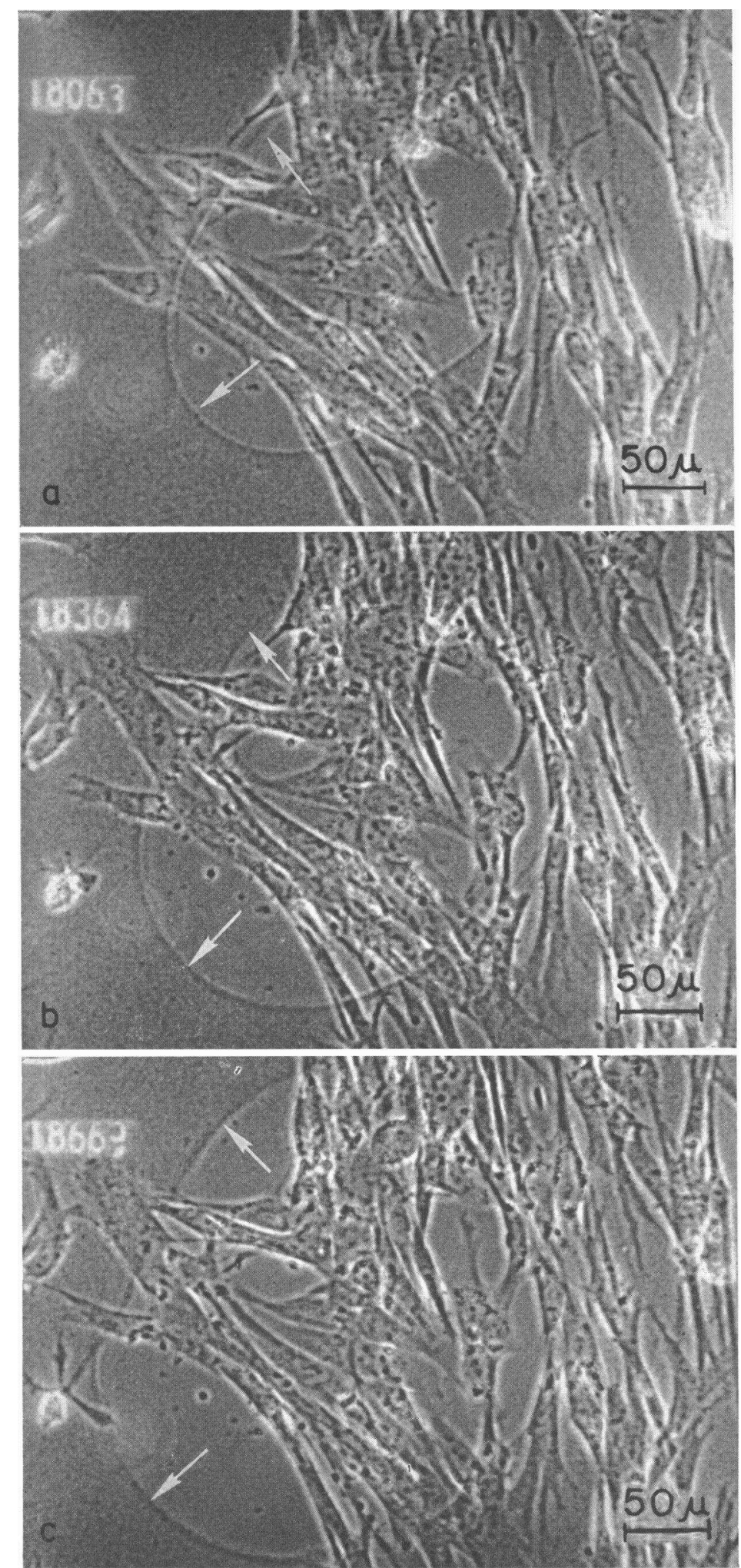

Figure 5 
exposed to lung cells for 1-5 days completely inhibited the activity of UK standards of 4.8-1.2 CTA U/ml. Supernates were not inhibitory towards plasmin or towards activator extracted from human heart tissue. Inhibitory activity against UK continued to accumulate until the cells died and activator activiy could not be demonstrated in any of the supernates.

Plasminogen activator activity was demonstrated, however, in lung cells throughout the culture period, although the number of active cells usually was small, $1 \%$ or less of the total population in living cultures. Lung cells lysed plasminogen-rich but not plasminogenfree fibrin indicating that activity was due to plasminogen activator. In lung cultures, the pattern of lysis differed from that in the kidney and was characterized by a later onset, slower progression, and more sharply demarcated borders around the lytic areas (Fig. $5 a, b, c$ ). Such pattern of lysis was peculiar to cultures of lung and other tissues which exhibited inhibitory activity.

Primary cultures of fetal lung. Results of these studies are summarized in Fig. 4. Plasminogen activator activity was demonstrated in fresh fragments before culture and in cells and media during culture. As in other tissues, activator activity from freshly cut fragments of fetal lung was not neutralized by the anti-UK sera. However, activator activity antigenically identical to that of UK began to accumulate after lung cells were implanted and survived or grew in culture.

The cultures contained mixed populations of cells which formed confluent sheets in 3-4 days. Cultures were then changed to BME and cells survived in this medium for 2-4 wk. Fibrinolytically active cells numbered up to $5-10 \%$ of the total cell population when living cultures were exposed to plasminogen-rich fibrin layers. Plasminogen-free fibrin was not lysed indicating that activity of lung cells was due to plasminogen activator.

Activator activity was detected in the supernates beginning 1-3 days after the cultures were changed to serum-free medium. The amounts increased thereafter, ranging from 0.5 to $3.0 \mathrm{CTA} \mathrm{U} / \mathrm{ml}$ per day. Activity continued to accumulate in the media after each refeeding until the cells died. Upon assay, nearly all of the activity was found to be neutralized by the anti-UK sera as shown in Fig. 4. Degree of neutralization ranged from 70 to $90 \%$ (average $85 \%$ ).

Random cultures, usually one of three or four, failed to yield activator activity or showed only traces of ac- tivity in the supernates despite continued viability of cells and prolonged exposure of media to cells. In these cultures fibrinolytically active cells were few, $0.1 \%$ or less of the total population. In addition, inhibitory activity was demonstrated in some of the supernates. When tested against UK standards, supernates inhibited the activity of $0.6-0.3 \mathrm{CTA} \mathrm{U} / \mathrm{ml}$, but showed no inhibitory activity towards plasmin or towards activator extracted from human heart tissue.

Subcultures of fetal lung. Primary cultures were subcultivated and were studied after each passage for up to 20 passages. Our subcultures were similar to those previously described (19). The cell population appeared to be predominantly fibroblast-like, although time-lapse records showed cells of varied morphology and behavior. Rapid growth of cells allowed splitting and replanting of cultures at 3- to 4-day intervals. After each passage, half of the cells were changed from their regular medium to BME, while the remaining cells were subcultivated further. Cultures received BME when cells formed large sheets, 2-3 days after trypsinization and passage. In serum-free medium, mitosis continued for 1-2 days and cells survived for periods up to $2 \mathrm{wk}$.

Plasminogen activator activity persisted in subcultures and continued to be neutralized by anti-UK sera. although to a lesser extent than in primary cultures. Summary of findings in Fig. 4 shows that activity accumulated in the supernates of subcultures in amounts up to $2.0 \mathrm{CTA} \mathrm{U} / \mathrm{ml}$ per day. Degree of neutralization ranged from 20 to $70 \%$ (average $50 \%$ ). Inhibitory activity similar to that of primary cultures also was detected in supernates of random subcultures.

Wi 38 diploid fetal lung cells (19) were studied serially from the 26th to 45th subculture. Morphology, growth, and survival of cells from Wi 38 were comparable with those of our subcultures. Plasminogen activator activity was demonstrated in cells and media of $\mathrm{Wi} 38$ after each passage, in amounts similar to those observed in our subcultures, as shown by results summarized in Fig. 4. Activity accumulated in the media of Wi 38 up to $2.5 \mathrm{CTA} \mathrm{U} / \mathrm{ml}$ per day and was neutralized partially by the anti-UK sera. Degree of neutralization ranged from 30 to $70 \%$ (average $55 \%$ ).

Subcultures of fetal heart. Fetal heart cells were studied after the $3 \mathrm{rd}, 12 \mathrm{th}$, and 13 th passages. Cultures from each passage were changed from their regular serumrich medium to BME when cells formed confluent sheets, 2-3 days after trypsinization. Heart cells continued to

Figure 5 Cells from a living culture of human lung tissue after exposure to plasminogen-rich fibrin. Arrows point to a lytic area in the center of the field. In contrast to the kidney culture in Fig. 2, the lytic area is enlarging slowly and shows sharply demarcated borders of fibrin. $5 \mathrm{~min}$ have elapsed between each sequence. Frames obtained from a phasecontrast time-lapse cinematographic record. 
divide for 1-2 days and they survived in serum-free medium up to $2 \mathrm{wk}$. Cell populations from fetal heart were epithelioid in appearance but exhibited variabilities in morphology and behavior when observed by time-lapse cinematography.

Plasminogen activator activity was demonstrated in cells but could not be elicited in the supernates (Fig. 4) even after the cell: medium ratio was increased, the cells were exposed to serum-free medium for up to 7 days, or were refed several times. When tested for the presence of inhibitors, supernates that were exposed to cells for periods ranging from $6 \mathrm{hr}$ to 5 days completely inhibited the activity of UK standards of $0.6-4.8 \mathrm{CTA}$ $\mathrm{U} / \mathrm{ml}$. Inhibitory activity against plasmin was elicited but in random supernates, one of two or three. These supernates inhibited the activity of 0.1 or less Remmert and Cohen $\mathrm{U}$ of plasmin.

Heart cells, however, exhibited fibrinolytic activity when living cultures were exposed to plasminogenrich fibrin layers. Pattern of lysis was similar to that observed in other cultures, such as those from lung, that were rich in inhibitory activity. Lytic areas were observed in up to $5 \%$ of the heart cells and were characterized by slow progression, sharply demarcated borders, and, frequently, complete arrest of lysis after 20-30 min. There was no lysis of plasminogen-free fibrin indicating that lytic activity of heart cells was due to plasminogen activator.

\section{DISCUSSION}

Lysis of fibrin coagula in tissue culture was observed by early workers (33-36) who attributed this activity to the release of fibrinolytic enzymes from injured or dead cells (34). Later studies demonstrated that lytic activity is due to plasminogen activator (13-15) and indicated that live, metabolizing cultures are a richer source of activator than disrupted cells or dying cultures $(9,13-15)$. Histochemical and immunological techniques facilitated further investigation of activator activity in culture. Histochemical methods provided means to study local fibrinolytic activity of cells (9) whereas specific antisera permitted immunologic identification of activator in the supernates $(8,9)$. Thus, it was observed that cells from the adult human kidney not only retain activator activity in culture, but continue to produce activator antigenically identical to that formed in the body in vivo and excreted in the urine, urokinase. The present study confirms these observations and yields further information on activator activity in the kidney and other human tissues from pre- and postnatal life.

Plasminogen activator was detected in supernatant fluids of cultures when serum was omitted and cells were fed a chemically defined medium such as Eagle's basal medium. Although serum was omitted primarily because of its content of inhibitors of fibrinolysis ( 37 , 38) which interfered with the assays, use of media with defined components also permits more precise investigation of metabolic aspects of cells $(18,20)$ and may facilitate study of the formation of biological material in vitro. Whereas chemically defined serum-free media are seldom capable of sustaining growth of cells in continuous culture (20), previous studies $(9,19)$ and our present observations indicate that cells can survive and metabolize for prolonged periods of time in such media. In addition, our observations indicate that in serumfree medium cells continue to form biologically active material, plasminogen activator, and that some of this material is antigenically identical with that produced in the body in vivo.

Two antisera which were used to identify plasminogen activator in the supernates of cultures have been described previously by Kucinski, Fletcher, and Sherry (8) and by White, Barlow, and Mozen (31). The antisera were found to neutralize the activity of $\operatorname{UK}(8,31)$ but not that of activator extracted from human tissues, tissue type activator, or that of a labile activator released in blood in vivo with various stimuli, plasma activator (8). The third antiserum, prepared by us in rabbits, exhibited similar characteristics, both in its neutralizing effect on UK and in its failure to react with other activator such as that extracted from human heart tissue and that obtained through stimulation with vasoactive drugs. Thus, the three antisera were specific for UK and capable of detecting activator antigenically identical with UK in culture fluids.

In vivo, $\mathrm{UK}$ is found in urine while tissues and other body fluids yield activators that differ from UK immunologically (8) and in other properties $(3,12)$. Although precise origin and interrelationship of the various naturally occurring activators in man, particularly tissue, plasma, and urine activators have not been entirely clarified, it has been shown that UK is produced by kidney cells $(8,9)$. Our present study confirms these observations. In living cultures of kidneys, activator antigenically identical with UK accumulated in the supernates after many complete changes of media, indicating continuous production of $\mathrm{UK}$ by the cultured cells.

Synthesis by kidney cells thus may account for UK that is found in the urine. However, whether and to what extent cells in tissues other than the kidney possess the ability to form UK type activator has not been hitherto established. Although UK has not been demonstrated in circulating blood (8), this does not exclude either local production of UK by cells in various organs or the presence of UK in the circulation, in amount or form that may not be easily detected by available techniques. The precise chain of events in the production, 
release, and fate of locally formed plasminogen activator $(s)$ is still largely unknown. Limitations in techniques further hinder in vivo investigation of small amounts of activator $(8,39)$ or of activator that may be bound to inhibitor (39). Tissues and cells, living in artificially controlled environments, were therefore used in the present study to investigate plasminogen activator produced in various organs and to determine whether UK type activator is formed in tissues other than the kidney.

In some of the cultures, particularly those from fetal heart and adult lung and bladder, investigation of plasminogen activator was hindered by inhibitory activity which was derived from cells and which accumulated in supernates. Although study of local fibrinolytic activity in these cultures showed cells with activator activity, presence of inhibitor prevented us from eliciting activator in the supernates and from establishing its identity. However, other tissues, both fetal and adult, yielded plasminogen activator in supernates and demonstrated that the ability to form UK type activator is not limited to the kidney. Thus, activator antigenically identical with UK accumulated in cultures of fetal lung and ureter indicating that cells from these tissues are capable of forming UK and that UK producing cells are distributed widely in the body. In the adult, activator antigenically identical with UK was demonstrated in culture supernates of renal blood vessels. In these cultures, activator activity was neutralized almost completely by the specific antisera and activity reaccumulated after many refeedings indicating continuous formation of UK by cells. Findings in renal blood vessels not only confirm studies of fetal cultures which show that cells other than those from kidneys possess the function of producing UK but also provide the first direct evidence which permits us to attribute such function to cells of blood vessels.

To assess the physiological significance of UK production in body tissues, particularly in blood vessels, it is pertinent to consider the fact that tissues are also a source of inhibitor(s) of UK activity. In the present study, inhibitory activity was demonstrated not only in cultures of adult lung and bladder and fetal heart, where rich inhibitor content appeared to have masked the presence of activator and may have reflected preferential survival or growth of inhibitor producing cells, but also in cultures of other tissues which yielded both UK type activator and inhibition of UK activity.

Inhibitors of fibrinolysis which act either on activator $(28,40)$ or on plasmin $(41)$ have been studied in body fluids and tissues although little is known about origin and nature of inhibitory substances, particularly of those acting against native activators of man. Thus, selective inhibition of UK has been investigated pri- marily in pregnancy $(28,40)$ where it is thought to derive from the placenta $(40)$. Our observations indicate, however, that such inhibitory activity is generally present in the body and that it is produced by cells of various organs both in fetal and adult life. Inhibitory activity accumulated in supernates of fetal lung, heart, and kidney, and in adult lung and bladder after many complete changes of serum-free medium. Such activity was directed selectively against UK and was found to mask the presence of UK type activator in at least two of the tissues in culture, fetal lung and kidney. Inhibitor may also hinder the detection of UK in blood or body tissues particularly if such activator is present in small amounts, or is in balance with or bound to inhibitor. While this concept is still hypothetical for events in vivo, it is consistent with our present observations in vitro which show that both UK and inhibitor are produced and released by cells from various organs beginning from the early stages of gestation.

Fetal cultures also clarified some aspects of the ontogeny of UK. Studies of plasminogen activator in prenatal life have indicated that activator is present in tissues during early periods of gestation (42) and that activity increases with growth and development of organs $(42,43)$. In the human fetus, plasminogen activator has been demonstrated in lung extracts (42) and in cultures of a lung cell line, Wi 38 (16). Little is known, however, about activator activity in other fetal organs, identity of fetal activator, and its relationship to that of adult life. In the present study, cells from the kidney, ureter, lung, and heart produced plasminogen activator as early as the 12th wk of gestation and thereafter. Furthermore, activator from these tissues showed reaction of identity with UK of adult origin when assayed with the antisera, indicating that cells in fetal life already possess the ability to form UK type activator. Studies of kidneys at progressive stages of gestation suggest, in addition, that the ability to produce UK parallels the development and maturation of fetal organs. Incomplete neutralization by anti-UK sera of activity from kidney and other fetal tissues in culture may be due to partial identity of fetal UK to UK of adults, or to the presence of more than one type of activator.

Plasminogen activator activity that differed from UK in immunoassays was elicited in supernates of freshly cut fragments of all tissues, fetal and adult, before culture and in supernates of mechanically traumatized explants during culture. Activator from these sources may be identical to that observed previously in fresh tissue fragments (2) and to "fibrinolysins" described by early workers in explants from various organs in vitro (34). Such activity may represent tissue type activator which differs immunologically from UK (8), and is found in nearly all tissues $(1,2)$, and is believed 
to be released through injury or death of cells (2). In contrast, UK appears to be primarily a product of living cells. In the present study, UK type activator began to accumulate in supernates only after cells survived or grew in culture and decreased sharply when cells were injured and died.

Activity differing from UK in immunoassays also was demonstrated after stimulation of fresh kidney fragments with vasoactive drugs, i.e., acetylcholine and nicotinic acid. Such activity may be identical with that of a labile activator, plasma type activator, which differs immunologically from UK (8) and is elicited in blood in vivo (4-8) and in the isolated kidney in vitro (32) after stimuli similar to those of our experiments. Stimulatory response was no longer demonstrated after tissue was cultured, although it was not apparent whether cells in culture failed to produce appropriate activator or lacked mechanism for its release.

While primary cultures exhibit specific function and generally reflect the enzyme pattern of the tissues of origin (18), such cultures from human sources are not always readily available in adequate numbers for biological studies in vitro. Serially propagated cells were therefore investigated to determine whether and to what extent they provide a suitable tool for the study of native activator activity of man. Since diploid and heteroploid cells may differ markedly in functional and other aspects (18-21), both types of cells were examined.

Diploid cells in serial culture have been shown to retain many of the characteristics of the tissue and cells of origin $(19,21)$. Our present study demonstrates that such cells also retain specific functions. Wi 38 diploid line, our lung subcultures, and diploid kidney line produced biological material antigenically similar to that formed in the body and in primary culture. Diploid lung and kidney subcultures continued to produce UK type activator after prolonged culture and many passages. In addition, subcultures continued to yield selective inhibition of UK activity. Serially propagated diploid cells are easily accessible in large numbers for biological studies in vitro $(19,21)$ and may facilitate investigation of the fibrinolytic system of man.

In contrast to diploid subcultures and primary cells, heteroploid cell lines retain few if any characteristics of the tissues of origin (18-21). Although activator activity has been described in cultures of several cell lines (13-15), identity of activator and its relationship to that in the original tissues and cells have not been explored. In the present study, heteroploid kidney line retained activator activity after prolonged subculture but, unlike diploid line and primary cells, did not yield UK type activator. Ability to produce such activator may have been lost in the process of cell alteration (18), activator may have been modified in culture, or new type of activator may have been acquired by the altered cells. Since cell lines have been regarded as a potentially rich source of plasminogen activator (13-15), it is pertinent to consider the fact that activator in heteroploid lines may differ from native activator in antigenic or other properties.

Study of local fibrinolytic activity in various tissues has been facilitated by histochemical techniques (44) which allow investigation of activator at the cellular level in fixed specimens $(9,44)$. In the present study, local fibrinolytic activity was explored further using living culture preparations which permitted direct and prolonged observation of cells and of dynamic aspects of lysis. Exposure of living cells to fibrin clots not only elicited greater activator activity but also revealed different patterns of lysis which appeared to be related to the presence or absence of local inhibitory activity. Slow progression or arrest of lysis in cultures that were rich in inhibitor, such as lung and heart, contrasted sharply with rapid spread of lytic areas in kidney cultures, particularly medulla. These observations suggest that living preparations reflect more precisely local fibrinolytic events than do fixed specimens and thus provide an additional model for the study of such events at the cellular level.

In conclusion, cells from human tissues are capable of specific functions in culture and are a source not only of fibrinolytic but also of inhibitory activity. Cells in culture thus provide means to investigate various aspects of the fibrinolytic system, particularly of features that may not be easily accessible for studies in vivo, but can be explored in tissues and cells living in artificially controlled environments in vitro.

\section{ACKNOWLEDGMENTS}

We wish to express our thanks to Mrs. E. Oller and Mrs. $\mathrm{H}$. Kroon for excellent technical assistance.

This work was supported by U. S. Public Health Service Grants HE 07057, HE 10573, and FR 048, and by a grant from the Otho S. A. Sprague Foundation.

\section{REFERENCES}

1. Albrechtsen, O. K. 1959. Fibrinolytic activity in the organism. Acta Physiol. Scand. 47 (Suppl. 165).

2. Astrup, T. 1966. Tissue activators of plasminogen. Fed. Proc. 25: 42.

3. Bachmann F., A. P. Fletcher, N. Alkjaersig, and S. Sherry. 1964. Partial purification and properties of the plasminogen activator from pig hearts. Biochemistry. 3: 1578.

4. Biggs R., R. G. Macfarlane, and J. Pilling. 1947. Observations on fibrinolysis. Experimental activity produced by exercise or adrenaline. Lancet. i: 402.

5. Fearnley, G. R., R. Revill, and J. M. Tweed. 1952. Observations on the inactivation of fibrinolytic activity in shed blood. Clin. Sci. (London). 11: 309.

6. Kwaan, H. C., R. Lo, and A. J. S. McFadzean. 1957. On the production of plasma fibrinolytic activity within veins. Clin. Sci. (London).16: 241. 
7. Holemans, R. 1965. Enhancement of fibrinolysis in the dog by injection of vasoactive drugs. Amer. J. Physiol. 208: 511 .

8. Kucinski, C. S., A. P. Fletcher, and S. Sherry. 1968. Effect of urokinase antiserum on plasminogen activators : demonstration of immunological dissimilarity between plasma plasminogen activator and urokinase. J. Clin. Invest. $47: 1238$.

9. Bernik, M. B., and H. C. Kwaan. 1967. Origin of fibrinolytic activity in cultures of the human kidney. J. Lab. Clin. Med. 70: 650.

10. Celander, D. R., and M. M. Guest. 1960. The biochemistry and physiology of urokinase. Amer. J. Cardiol. 6: 409.

11. von Kaulla, K. N. 1963. Chemistry of thrombolysis: Human fibrinolytic enzymes. Charles C Thomas, publisher, Springfield. 96.

12. Kok, P., and T. Astrup. 1969. Isolation and purification of a tissue plasminogen activator and its comparison with urokinase. Biochemistry. 8: 79.

13. Barnett, E. V., and S. Baron. 1959. An activator of plasminogen produced by cell culture. Proc. Soc. Exp. Biol. Med. $102: 308$.

14. Painter, R. H. 1961. The plasminogen activator from kidney tissue cultures. In International Symposuim: Anticoagulants and Fibrinolysins. R. L. MacMillan and J. F. Mustard, editors. Lea \& Febiger, Philadelphia. 351.

15. Painter, R. H., and A. F. Charles. 1962. Characterization of a soluble plasminogen activator from kidney cell cultures. Amer. J. Physiol. 202: 1125.

16. Kucinski, C. S., and A. P. Fletcher. 1967. Immunological studies with urokinase. Fed. Proc. 26: 2193. (Abstr.)

17. Committee on Terminology, Tissue Culture Association. 1967. Proposed usage of animal tissue culture terms. Cytogenetics (Basel). 6: 161.

18. Levintow, L., and H. Eagle. 1961. Biochemistry of cultured mammalian cells. Ann. Rev. Biochem. 30: 605.

19. Hayflick, L., P. S. Moorhead. 1961. The serial cultivation of human diploid cell strains. Exp. Cell Res. 25: 585.

20. Eagle, H., and L. Levintow. 1965. The metabolic characteristics of serially propagated cells. In Cells and Tissues in Culture: Methods, Biology and Physiology. E. N. Willmer, editor. Academic Press Inc., New York. 1: 276.

21. Hayflick, L. 1963. Human diploid cell strains as hosts for viruses. In Gustav Stern Symposium on Perspectives in Virology III. M. Pollard, editor. Harper \& Row, Publishers, New York. 213.

22. Rose, G. G., C. M. Pomerat, T. O. Shindler, and J. B. Trunnell. 1958. A cellophane-strip technique for culturing tissue in multipurpose culture chambers. J. Biophys. Biochem. Cytol. 4: 761.

23. Eagle, H. 1955. Nutrition needs of mammalian cells in tissue culture. Science (Washington). 122: 501.

24. Eagle, H. 1959. Amino acid metabolism in mammalian cell cultures. Science (Washington). 130: 432.

25. Lassen, M. 1958. The estimation of fibrinolytic components by means of the lysis time method. Scand. J. Clin. Lab. Invest. 10: 384 .
26. Brakman, P. 1965. Bovine fibrinogen without detectable plasminogen. Anal. Biochem. 11: 149.

27. Astrup, T., and S. Müllertz. 1952. The fibrin plate method for estimating fibrinolytic activity. Arch. Biochem. Biophys. 40: 346.

28. Brakman, P., and T. Astrup. 1963. Selective inhibition in human pregnancy blood of urokinase induced fibrinolysis. Scand. J. Clin. Lab. Invest. 15: 603.

29. Sgouris, J. T., J. K. Inman, K. B. McCall, L. A. Hyndman, and H. D. Anderson. 1960. The preparation of human fibrinolysin (Plasmin). Vox Sang. 5: 357.

30. Lassen, M. 1952. Heat denaturation of plasminogen in the fibrin plate method. Acta Physiol. Scand. 27: 371.

31. White, W. F., G. H. Barlow, and M. M. Mozen. 1966. The isolation and characterization of plasminogen activators (Urokinase) from human urine. Biochemistry. $5: 2160$.

32. Holemans, R., J. G. Johnston, and R. L. Reddick. 1965. Release of plasminogen activator by the isolated perfused dog kidney. Nature (London). 208: 291.

33. Loeb, L. 1903. On the coagulation of the blood in its relation to thrombosis and the formation of fibrinous exudate. Montréal Med. J. 32: 507.

34. Fleisher, M. S., and L. Loeb. 1915. On tissue fibrinolysins. J. Biol. Chem. 21: 477.

35. Fischer, A. 1925. Beitrag zur Biologie der Gewebezellen. Eine vergleichend-biologische Studie der normalen und malignen Gewebezellen in vitro. Arch. mikr. Anat. $u$. Entwicklungsmech. 104: 210.

36. Santesson, L. 1935. Characteristics of epithelial mouse tumor cells in vitro and tumor cells in vivo: a comparative study. Acta Pathol. Microbiol. Scand. Suppl. 24.

37. Müllertz, S. 1957. Activation of plasminogen. Ann. N. Y. Acad. Sci. 68: 38.

38. Shulman, N. R. 1952. Studies on the inhibition of proteolitic enzymes by serum. II. Demonstration that separate proteolytic inhibitors exist in serum; their distinctive properties and the specificity of their action. J. Exp. Med. 95: 593.

39. Brakman, P. 1967. Fibrinolysis. A standardized fibrin plate method and a fibrinolytic assay of plasminogen. PhD. Thesis. University of Amsterdam. Scheltema and Holkema. N. V., Amsterdam.

40. Kawano, T., K. Morimoto, and Y. Uemura. 1968. Urokinase inhibitor in human placenta. Nature (London). 217: 253.

41. Norman, P. S. 1966. Antiplasmins. Fed Proc. 25: 63.

42. Ambrus, C. M., D. H. Weintraub, W. R. Niswander, and J. L. Ambrus. 1965. Studies on hyaline membrane disease. II. The ontogeny of the fibrinolysin system. Pediatrics. 35: 91 .

43. Pandolfi, M. 1967. Localization of fibrinolytic activity in the developing rat eye. Arch. Ophthalmol. 78: 518.

44. Kwaan, H. C., and T. Astrup. 1967. Demonstration of cellular fibrinolytic activity by the histochemical fibrin slide technique. Lab. Invest. 17: 140. 